\title{
Balancing Memory and Material at the Lower East Side Tenement Museum
}

\author{
Gabrielle A. Berlinger
}

\begin{abstract}
Founded in a nationally landmarked apartment building on the evergentrifying Lower East Side of Manhattan, New York, the Lower East Side Tenement Museum is an historic site of immigrant social history and material culture. Constructed in 1864 and occupied by over 7,000 immigrants until its closing in 1935, this building has withstood constantly rising visitorship each year since its opening as a museum in 1988. With apartment spaces restored for the public to explore without roped-off restriction, this time capsule of domestic immigrant life requires continual maintenance to preserve its historic physical fabric. Through interviews with the Museum staff and the Preservation Advisory Committee (conservators, architectural historians, curators), as well as documentation of technical processes carried out in the preservation process, this ethnographic study investigates the questions and compromises that arise in the preservation of the tangible and intangible heritage contained within an historic structure in constant use. Which narratives are reconstructed through the Museum's decisions to restore certain material features of the building while allowing others to decay? What are best practices for interpretation and preservation when a museum's success results in the gradual destruction of its main artifact (the building) through use? This study explores the intersection of museum mission and practice, heritage construction, and historic preservation at a site both sustained and destroyed by its increasing success.
\end{abstract}

[Keywords: historic preservation, heritage conservation, vernacular architecture, house museums, intangible heritage, immigrant. Keywords in italics are derived from the American Folklore Society Ethnographic Thesaurus, a standard nomenclature for the ethnographic disciplines.]

\footnotetext{
* This peer-reviewed contribution was accepted for publication in Museum Anthropology Review on January 2 , 2017. The work is licensed under the Creative Commons Attribution 4.0 International License. To view a copy of this license, visit http://creativecommons.org/ licenses/by/4.0/
} 


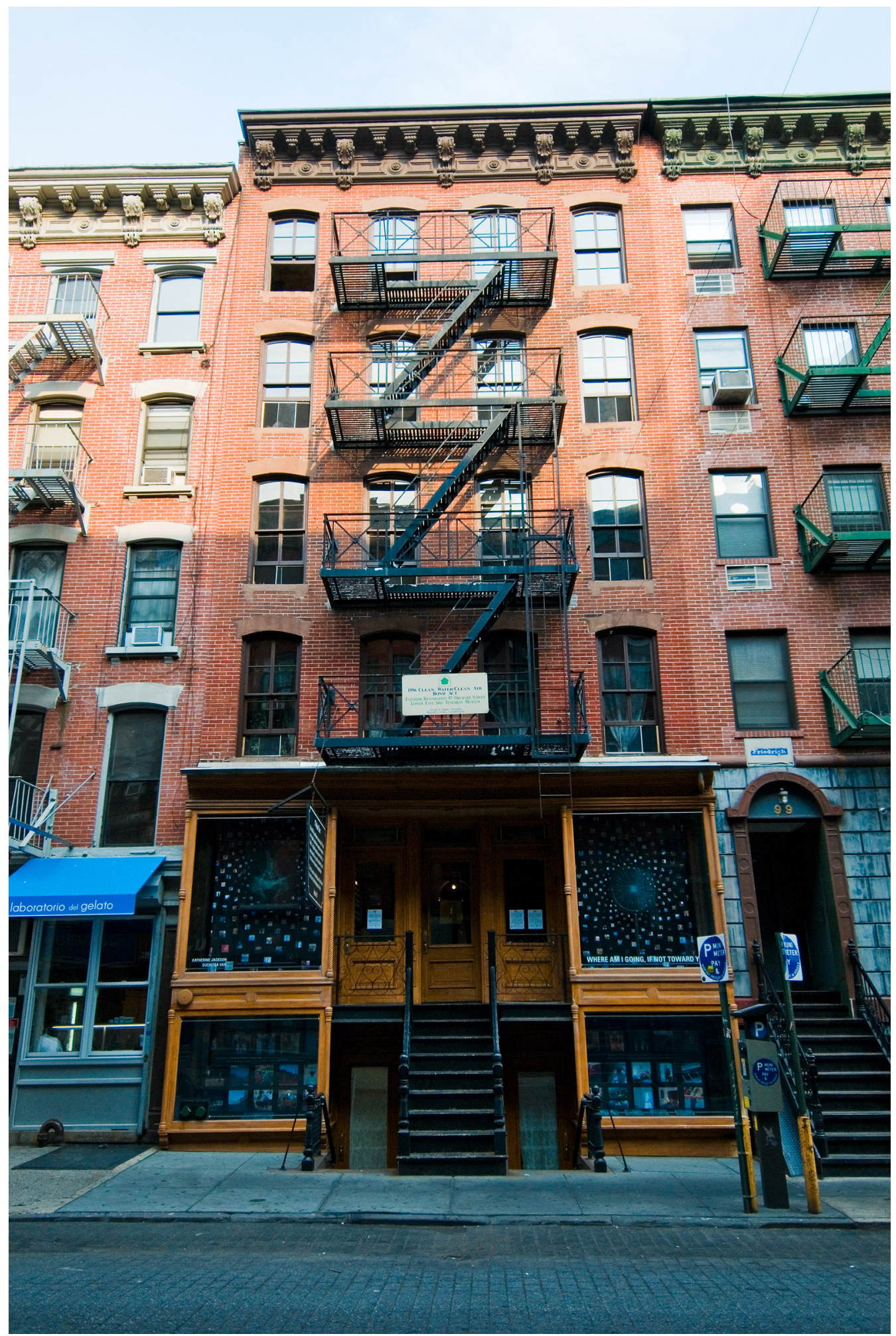

Figure 1. Façade of 97 Orchard Street. Courtesy of the Lower East Side Tenement Museum. 


\section{The Museum Story}

Standing at 97 Orchard Street, in the center of Manhattan's ever-more chic Lower East Side, is an unassuming five-story apartment building. Wood-framed and stacked with brick, it was built in 1863 to 1864 before housing laws had been introduced in New York City. This tenement building is flanked by similar tenements on either side, which share its "Italianate-style" façade - a typical style of their time (see Figure 1). Orchard Street's architectural character reaches back to the late nineteenth to early twentieth century period, when this area of the Lower East Side was exploding into an overpopulated new home for the waves of German, Irish, Italian, and Eastern European Jewish immigrants who flooded into New York seeking a new life. By 1910, the neighborhood's population had reached its peak density at five hundred fifty thousand people, the most crowded blocks, including Orchard Street, numbering around two thousand two hundred residents each (Dolkart 2006). 97 Orchard Street, a building at the center of this expansion, housed twenty immigrant families in four apartments on each of the building's five floors, on a lot intended for a single-family residence (Figure 2). Each apartment measured three hundred twenty five square feet and consisted of three small rooms - a parlor, a kitchen, and a bedroom-with two commercial spaces in the basement. Originally constructed without indoor gas or plumbing, and with only one room in each apartment exposed to direct sunlight, this tenement housed an estimated seven thousand immigrants from 1864 until 1935, when its landlord refused to bring the building up to the latest housing codes, evicted the remaining tenants, and sealed the building shut for the next 50 years.

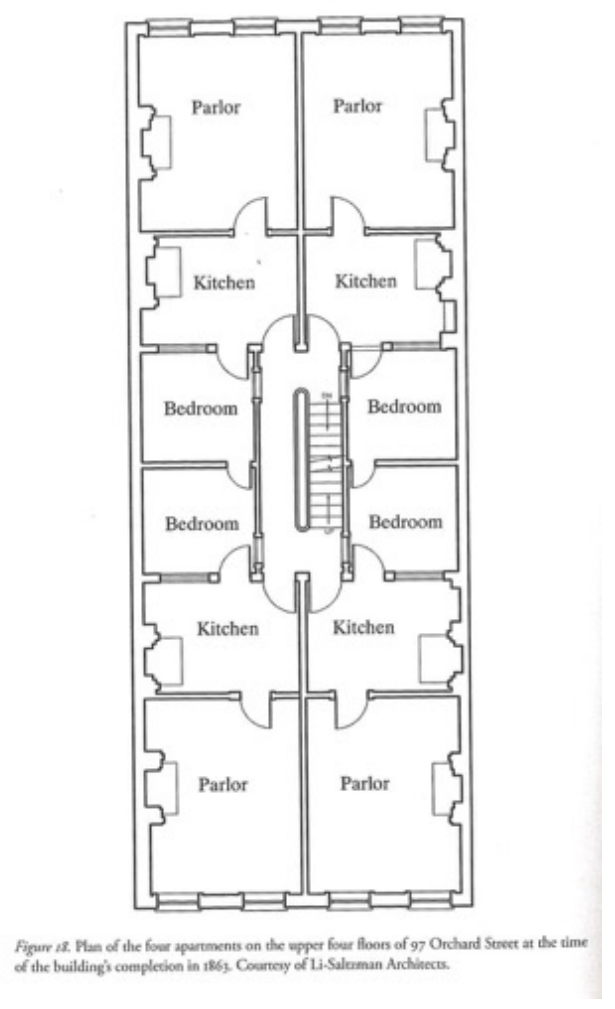

Figure 2. Floor plan of the four apartments on the upper four floors of 97 Orchard Street when building construction was completed, 1864. Courtesy of Li-Saltzman Architects. 
In 1988, half a century after the apartments in 97 Orchard were condemned, two social activists, Ruth Abram and Anita Jacobson, discovered the building (Figure 3). Although the structure was in a state of complete disrepair, they immediately recognized this "urban time capsule"- the building's interior untouched since 1935-and envisioned how the neglected layers of the building's historic fabric could narrate the social histories and cultural experiences of the thousands of immigrants who had occupied its space. They catalyzed the building's restoration and the development of what would become the Lower East Side Tenement Museum, the only tenement building in New York whose interior was still intact. According to the Lower East Side Tenement Museum's Preservation Philosophy (2006), "97 Orchard Street is a remarkable survivor from the early period of tenement house construction" revealing "72 years of urban family life, early tenement construction, housing reform, and interior decoration." This unique building tells the economic, social, cultural, and personal histories of working-class immigrants of nineteenth and twentieth century New York as no other site or structure can-through the material evidence and individual experiences of the people who lived, worked in, designed, and adapted these spaces as expressions of their lives.

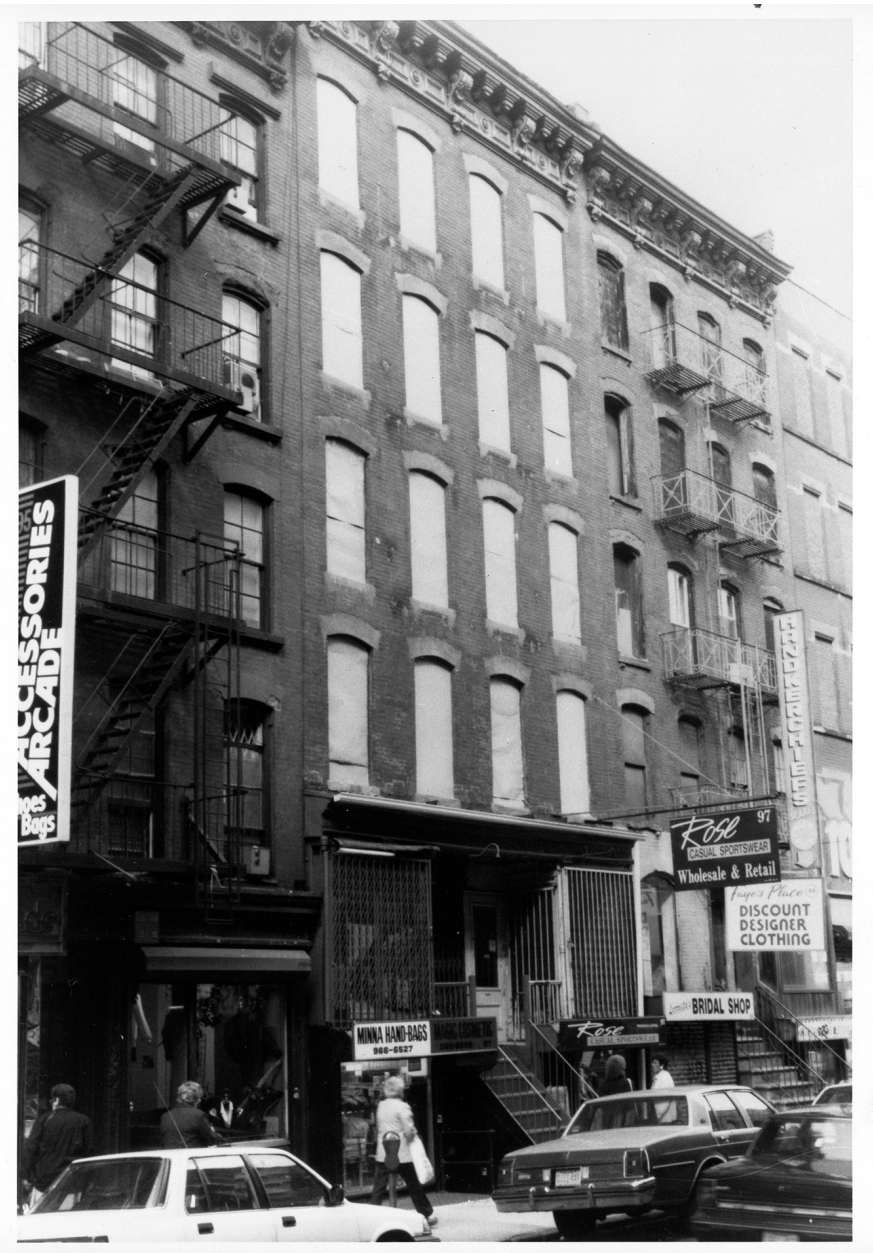

Figure 3. Boarded up façade of 97 Orchard Street, 1988. Courtesy of the Lower East Side Tenement Museum. 
When Ruth Abram and Anita Jacobson initiated the restoration of 97 Orchard Street, they sought to prove that "the history of 'ordinary' people is worthy of inclusion in the historical record; indeed, that the record cannot be fully understood if they are excluded" (Lower East Side Tenement Museum [LESTM], "Statement of Significance"). After the first apartment was opened to the public, a series of formal recognitions of the site's historic and cultural value ensued. In 1992, the building was listed on the National Register of Historic Places. In 1994, it was designated a National Historic Landmark, in 1998 it was named a Lower East Side Tenement National Historical Site and an affiliated area of the National Park System, and in 2001 it was listed as a contributing building within the National Register's Lower East Side Historic District.

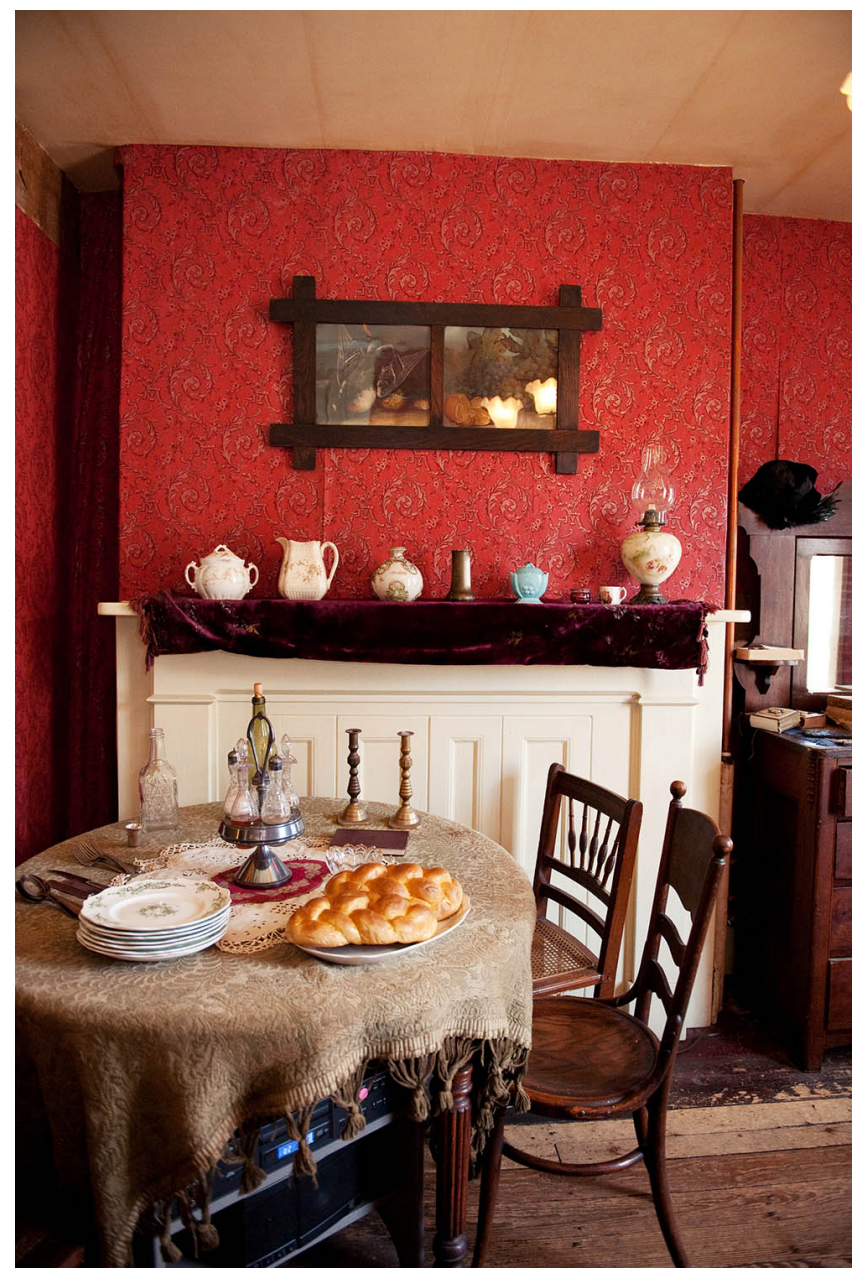

Figure 4. Recreated interior of the Rogarshevsky Family Apartment. Photo by Keiko Niwa. Courtesy of the Lower East Side Tenement Museum.

Through these years since its discovery and restoration, the museum has gradually expanded its exhibition space and public outreach. Today, the Tenement Museum has opened seven spaces for public touring (six recreated apartments-Confino, Gumpertz, Baldizzi, Levine, Rogarshevksy, and Moore - and a commercial space - a saloon and partial ruin - on the basement floor), each one restored to a particular historical moment in the lives of the actual families who lived and worked in those spaces (see Figure 4). These spaces, along with thematic tours of the 
surrounding neighborhood, serve the museum's founding vision of uncovering neglected personal histories that can "promote tolerance and historical perspective through the presentation and interpretation of the variety of immigrant experiences on Manhattan's Lower East Side, a gateway to America" (LESTM, original mission statement).

In order to fulfill this original mission statement, the museum employs a remarkable variety of strategies to research, restore, and present the building's social and physical history. The education and curatorial staff locates family members and friends of former residents of 97 Orchard Street to conduct in-depth oral histories, examines family and municipal archives for documents related to the building's history and occupants, and combs annual census reports for demographic data and clues as to when individual residents changed occupations or why they disappeared. They also study interior crime scene photographs taken from 1863 to 1935-some of the only domestic interior photographs from that era - to accurately reconstruct the physical designs of the building's apartment interiors; hire archaeologists to dig into the ruined apartments and unearth buried artifacts such as receipts, kitchen utensils, dolls, coins, and ticket stubs from beneath floorboards and behind fireplaces; and consult with historians and cultural scholars to interpret the significance of these traces of social, cultural, and political experience. Their ongoing research methods are cross-disciplinary, allowing for the building's histories to continue to evolve. When new information sheds light on inaccuracies in the museum's telling of a former resident's life story or its depiction of a recreated domestic scene, the museum staff rewrites the narratives and redesigns the rooms to reflect the updated information. And, when changes are not made in light of new information, the staff explains that deliberate choice to the visiting public. The candor built into its ongoing research process reveals the museum's commitment to transparency.

Comparable to its diversity of research strategies is the Tenement Museum's restoration process. Rather than employing a single approach to address the its fragile physical fabric, which includes the historic artifacts discovered in the building as well as the building itself, the museum relies upon a host of experts: conservators, architectural historians, architects, climate control specialists, structural engineers, and curators to recommend distinct treatments for distinct materials. As a result, different parts of the building have been restored (the stairwell), conserved (plaster ceilings and wallpaper), recreated (the furnishings in the apartments), and preserved (the unfinished apartments, also described as in a state of "stabilized ruin"). Employing such a diversity of treatments in one historic site reveals the cultivation of best practices with regard to the maintenance of the museum's material culture and adherence to its mission statement.

Finally, the Tenement Museum's presentation of its material also represents an uncommon approach to education and the public. Rather than recreate period rooms behind red velvet ropes marked with small object labels that describe the provenance and purpose of each item, which is often the case in historic house museums, all spaces in 97 Orchard Street are fully open for visitors to enter. To enhance the sense of experiencing the building as the original residents did, not a single object label can be found on its walls. To enable such freedom of movement, however, visitors may not wander through the building on their own, but must buy tickets to a themed tour of the building led by educators, or trained guides, who lead small groups through the physical spaces and narrate the social histories of the apartments' former occupants. These tours address pressing issues in the immigrant families' lives such as garment industry work and 
sweatshop labor, religious practices, economic depression, and ethnic prejudice. Providing meaningful context and stimulating discussion that bridge historic realities with contemporary circumstances, the educators enable visitors to be fully present in the apartment spaces, to see, touch, smell, and imagine the lives of former tenants as they listen to their life stories unfold. Visitors are encouraged to walk through the tight, three-room apartment spaces, the closeness compounded by the sounds of creaking floorboards below one's feet and the sight of peeling paint within arm's reach. They experience the cramped quarters where daily work, religious practice, family rearing, and social life all took place, and are overwhelmed by the affective power of this Museum's immersive experience.

\section{Competing Priorities}

Since its opening, the Tenement Museum's popularity has soared and currently over two hundred thousand people visit it per year. On April 18, 2014, attendance reached its peak for a single day when one thousand people toured the structure between 10 a.m. and 5 p.m., ascending and descending its five-floor wooden staircase, walking along its sloped floorboards, beneath its cracked plaster ceilings, and through its narrow hallways covered with up to twenty layers of chipped paint and peeling wallpaper (see Figure 5).

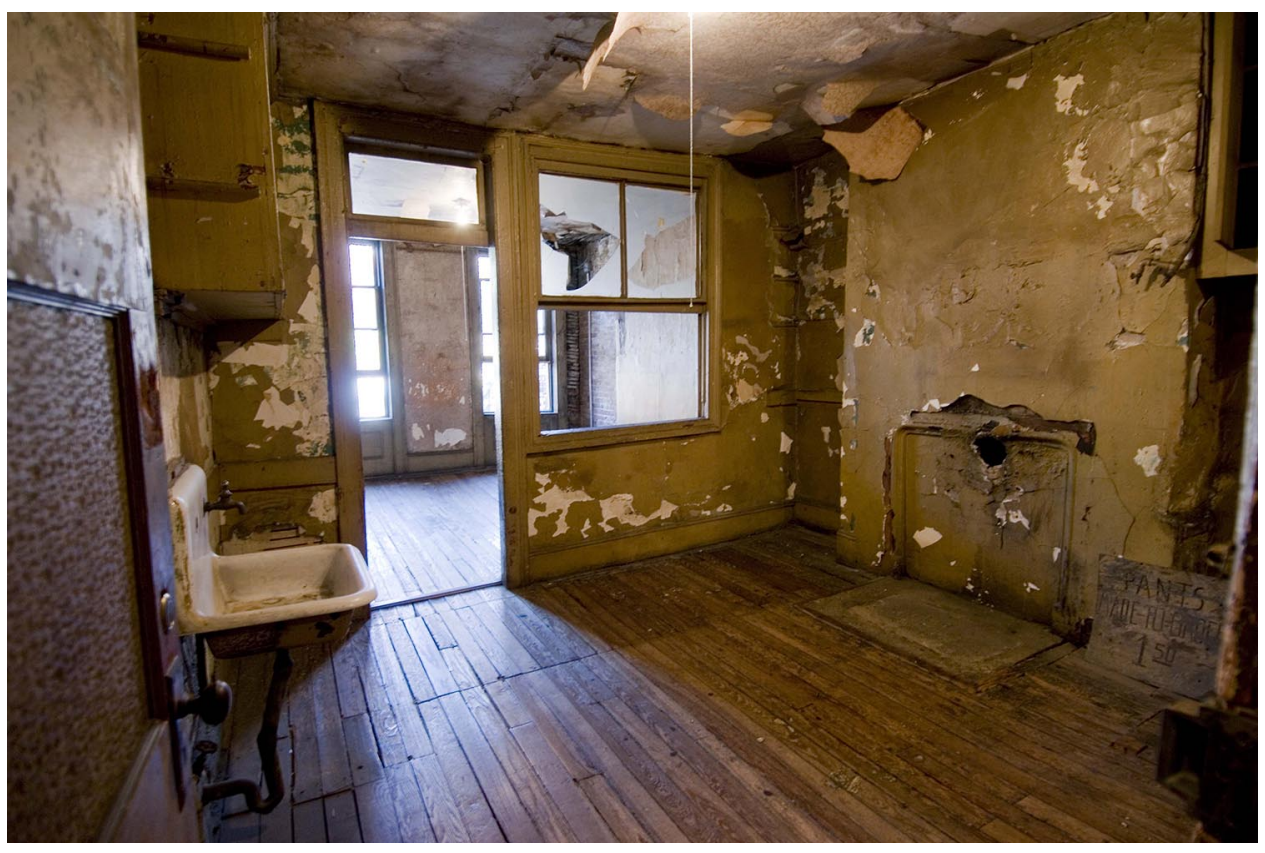

Figure 5. Preserved interior of a "stabilized ruin" apartment. Photo by Keiko Niwa. Courtesy of the Lower East Side Tenement Museum.

The introduction to the museum's Conservation Management Plan of 2006, which is a physical assessment of the building and a philosophical inquiry into its preservation mission, acknowledges a conflict: "heritage sites such as 97 Orchard simultaneously need to be both presented to, and protected from, the public." Seven years later, in 2013, during a Preservation Advisory Committee meeting held at the Museum to strategize a new plan of action for the future, two contracted structural engineers 
presented the results of months of vibration monitoring in the building. The cause of recently falling pieces of ceiling plaster in upper-floor apartments, they concluded, was clear: "we've completely confirmed that it's the people!" Ironically, the Preservation Advisory Committee had been formed to protect the building for the very people who were compromising it. This example epitomizes the Tenement Museum's dilemma: how to reconcile the needs and goals of the its tangible and intangible heritages. $^{2}$

This research project investigated the conflicts and compromises that arise in preserving the museum's physical and social histories, a situation that requires a constant re-negotiation of competing demands: (1) the museum's primary commitment to telling the residents' histories through an immersive visitor experience; (2) the dependence of $70 \%$ of the museum's budget on visitor ticket sales (it remains open 362 days a year); and (3) the accelerating deterioration of the historic structure, the museum's main artifact, due to rising visitorship. 97 Orchard is an artifact that is continually touched, retouched, and repaired in order to serve the public. A fundamental and compelling philosophical question is whether certain physical features of the structure must remain original in order to serve the museum's mission, or whether the entire building can be gradually reconstructed over time. How much physical intervention is appropriate at this historic site? Is there a point in the ongoing preservation at which the visitor experience will be compromised?

Historic preservation architect Judith Saltzman writes in the Museum's Preservation Philosophy that,

The preservation of 97 Orchard Street is predicated on retaining the palpable sense of history contained within its walls, and on providing both the experience of the tenement as people lived there, and as it was found. To do so, it is critical to identify appropriate ways of treating the building's historic fabric. The philosophy for the treatment of 97 Orchard Street rests on several key goals: (1) to provide safe public access to the historic resource; (2) to respect the contributions of all periods of the site's historic significance (1863-1935); (3) to maximize the retention of the site's historic character; (4) to minimize the loss of extant historic fabric; (5) to integrate historic preservation with the interpretive program.

As the historic fabric continues to degrade with the museum's success, however, how are the material preservation, historic character, and public safety continually re-balanced? The Tenement Museum's updated mission statement now reads:

The Tenement Museum preserves and interprets the history of immigration through the personal experiences of the generations of newcomers who settled in and built lives on Manhattan's Lower East Side, America's iconic immigrant neighborhood; forges emotional connections between visitors and immigrants past and present; and enhances appreciation for the profound role immigration has played and continues to play in shaping America's evolving national identity. ${ }^{3}$

How does this mission influence, and how is it influenced by, the changing state of its primary artifact - a slowly disintegrating building? As both artifact and educational tool, 97 Orchard Street preserves and reconstructs both the tangible and intangible heritages of its occupants; and, 
although they are tightly interwoven, tensions do exist within that fabric. This article explores some of those tensions by presenting different perspectives of the Tenement Museum's staff regarding the relationship between the building's physical restoration and the museum's mission. It also probes the conceptual framing of the museum's work, the challenge faced by the museum's staff regarding the term and concept of "heritage" in the context of the museum's work and its Lower East Side neighborhood.

\section{Voices: Assessing Conflicts and Compromises}

As a folklorist interested in vernacular architecture, I approached 97 Orchard Street as a material expression of the social histories and values of its immigrant builders and users; its ongoing reconstruction aims to restore those human stories and values with which the building was imbued throughout its use. During two years of ethnographic research, from 2013 to 2014, I observed ongoing restoration work at 97 Orchard Street, including vibration monitoring, conservation of linoleum flooring, wallpaper, and ceiling plaster. I attended biannual Preservation Advisory Committee meetings at which architectural historians, structural engineers, conservators, climate control specialists, historic preservation architects, and museum staff researched and assessed the state of the structure and suggested preservation strategies for the future. I also interviewed members of the Tenement Museum staff and the Preservation Advisory Committee to gather various perspectives on how to preserve the historic fabric of the structure while fulfilling the museum's mission. Each specialist's expert knowledge shed a unique light on the goal of protecting the Museum's historic material and interpretive mission. My aim was to discover the points of convergence and divergence among these perspectives. More broadly, the process of resolving the two conflicting goals of the Tenement Museum contributes to museum and heritage studies as a contemporary example of how to balance conservation and interpretation in historic house and living history museums.

In 1983, architectural historian Dell Upton emphasized the importance of analyzing the symbolic meaning of buildings and objects in order to understand how people construct their environments (Upton 1983, 278). Building upon this notion and the sociolinguistic work of Michael Ann Williams and M. Jane Young in their study of vernacular architecture (1991), a decade later, folklorist Joseph Sciorra observed that, "what people say about the houses in which they live, the spaces in which they work, and the buildings where they worship offers a rich source of documentation on the social and symbolic use of vernacular architecture" (Sciorra 1993, 204). Guided by these views, I approached the construction, modification, preservation, and use of 97 Orchard Street through both material analysis of its changing physical structure, and ethnographic analysis of the ideas of individuals who interact with it.

Between 2002 and 2006, the museum published an institutional "Preservation Philosophy" and a "Conservation Management Plan" (CMP), a multi-year assessment of the structure of the building that discussed such areas as "Visitor Impact and Capacity Analysis," "Architectural Cyclical Maintenance Plan," "Housekeeping Plan," and probed the issue of authenticity by considering the appropriate levels of restoration needed to maintain both the museum's structural integrity and the integrity of its educational mission. Regarding the temperature and relative 
humidity in the building, for example, it asks, "how much climate control is really necessary for the Lower East Side Tenement Museum?" It concludes that,

The public spaces in the building should not have more than the minimum heating for visitor comfort. Anything more will be a distortion of the message: THIS IS THE WAY THINGS WERE...Full environmental controls would make the experience feel quite inauthentic.

Later, the plan reasserts the need to preserve the building's "cramped hallways, dark rooms and limited ventilation," reaffirming the "authenticity" of the experience of tenement life. Ultimately, the plan declares that public safety and that the visitors do not ultimately destroy the historic fabric of the tenement remain the on-going challenges (CMP 2006).

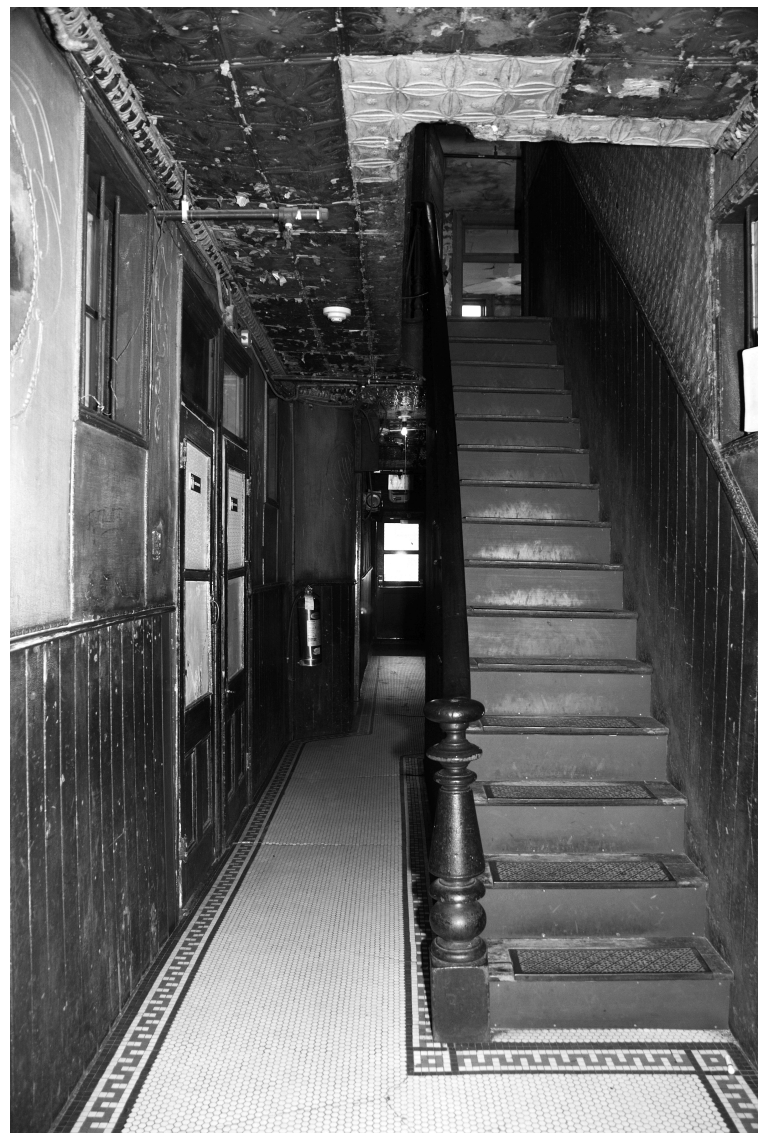

Figure 6. Mahogany banister from Cuba installed in 1863. Photo by Keiko Niwa. Courtesy of the Lower East Side Tenement Museum.

To Judith Saltzman, historic preservation architect and consultant to the Tenement Museum since its founding, sensory interaction with the building is critical for the visitor experience. Of all the building's features, the one that she considers most essential to preserve is the original mahogany banister from Cuba installed in 1863, which all the immigrants who lived in the building touched (see Figure 6). "There is a difference between something that all these people have touched, and something that's been created to look like it. Their DNA is part of that 
material," Saltzman said; "it's the intangible aspect" of the Tenement Museum experience. To illustrate her point, Saltzman described a friend's reaction to the cleaned and preserved main building of Ellis Island, in contrast: "there's no smell here!" her friend exclaimed. For Saltzman, in addition to physical touch, the smell of the air and the level of illumination are critical to evoking a holistic experience of the past. The mahogany banister, a locus of shared touch, embodies the "palpable sense of history" that Saltzman hopes will be preserved in coming decades.

Pamela Keech, consulting curator, similarly located meaning in material when she spoke of the building's entryway:

One of my favorite things is the electric meter bank just past the stairway. You think about how many tenants lived here and were concerned about electricity use, and that electricity only came in here around 1930, and how much it changed life when it did! I also love the mailboxes back there because they have the apartment numbers on them and you think about all the people who touched those mailboxes and got their mail every day, and then the new tenants who moved in and used them after that... These things are like arborglyphs - carved writing in trees that evolve with the tree's growth, the letters bulging out and changing shape... they're alive.

Keech then broadened her perspective on what must be preserved to include "anything that you know so many people have touched," especially because the museum allows visitors to continue that history by still touching these things today. Keech reads the materiality and structure of the building as belonging to "someone's home," grounding her interpretation of "authenticity" in these present, private moments of domestic encounter. When asked how she might define the notion of "authenticity" in the context of 97 Orchard Street, Keech replied, "when visitors crywhen you see the tears in their eyes."

Founder Ruth Abram offers a contrasting idea of authenticity in the museum. For her, tangible contact with the original features of the building is not as important or transformative as visitors' encounters with its story:

I think of the Museum as a set design... So, yes, I think you can replace it all. We'd have to close the museum if I didn't think we were approximating the experience and the feeling. But I think the most important thing in terms of authenticity is that the museum is telling actual stories of people who actually lived in the building...in an intriguing and exciting way, in an atmosphere that approximates what it was. I think that's fair enough, as long as we're honest.

And indeed, when the Museum realized after completing the first re-creation in the Gumpertz apartment that it had inaccurately wallpapered the parlor, they left the mistake and incorporated the story into their tour (see Figure 7). Transparency is a key pillar of their educational and interpretive approach. Regarding preservation and reconstruction, Abram added:

I'm all for doing as much as possible, but not to the exclusion of letting people in. The idea from the beginning was we're inviting the American public home to meet their 
families and you don't invite people home and have velvet ropes separating them from the place.

For Abram, "authenticity" in the museum is rooted in empathy for the immigrants' experiences:

That you stand inside a space and listen to the story of the struggles and triumphs of another human being, and realize that they were quite similar to you, facing perhaps dissimilar circumstances, and find a way to empathize with them and their story-that's authentic. We're not talking about this room and that table and this vase; you can't do that with poor people. They had to be measured by the content of their dreams, not the content of their apartment.

Abram prioritizes the intangible heritage of the museum - the lived experiences of the tenants of 97 Orchard - although it is the tangible artifact of the building itself, the cold, the dark, the smell, the cramped hallway, the original wooden banister, and the mailboxes, which affectively evoke a visitor's experience of empathy.

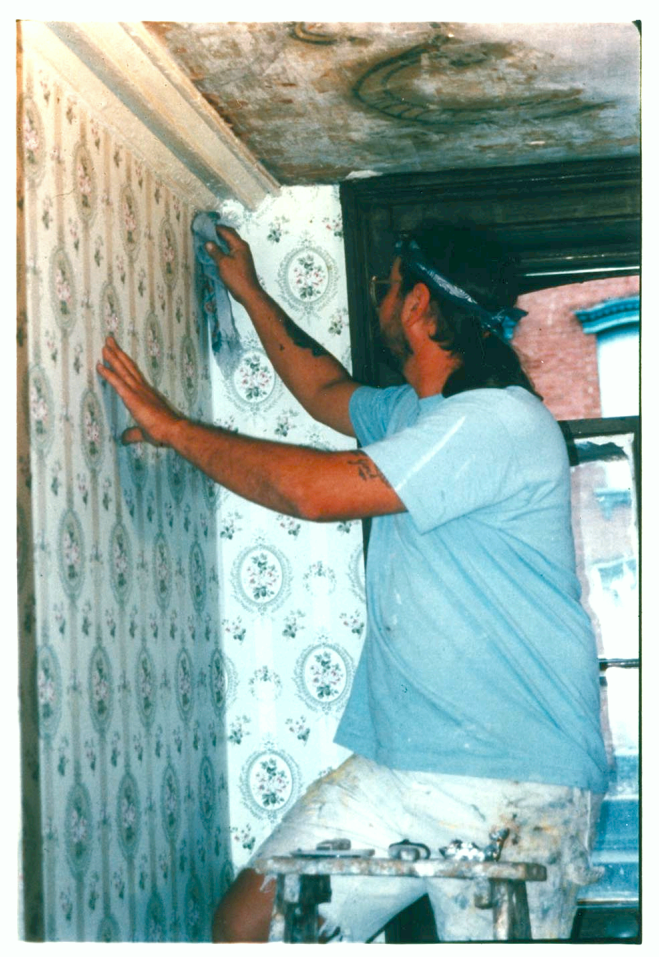

Figure 7. Restoration carpenter Kevin Groves installs reproduction wallpaper in the Gumpertz Family Apartment, 1994. Courtesy of the Lower East Side Tenement Museum.

\section{Authenticity and Heritage on the Lower East Side}

The elusive concept of authenticity factored significantly in discussions about which materials in the building to preserve and how they should be treated. Conversations with the education staff, in particular, however, revealed the relationship between the notion of authenticity and heritage, 
another contested concept in the context of the tangible and intangible cultural preservation. Adam Steinberg, Senior Education Associate at the Tenement Museum, noted that,

I think we collectively avoid [the word heritage] at the Museum, but not consciously. For me, heritage connotes proprietary ownership of culture and I think that's something we are uncomfortable with at the museum because it gets in the way of our mission of drawing connections. Once you talk about heritage, you start talking about authenticity, and that's a road you don't want to go down. Authenticity is a relationship you have to something, it is not inherent in that thing.

Like Abram, Steinberg views authenticity as relational and he has a vested interest in not engaging that concept or the notion of heritage on his tours because of their power to exclude groups of people. Critical to Steinberg's perspective is the particular context of the Lower East Side of Manhattan, an historically-iconic, lower-income, immigrant neighborhood now become a hipster hotspot where "institutions tend to be part of a specific community," and where linguistic, cultural, economic, and geographic barriers exist. In this current environment, "if you don't identify with one group or the other then who are you?" asked Steinberg, continuing with the museum's philosophical position, "how do you convey to all these people that no, we don't belong to a single group?" In the museum's desire to appeal broadly and equally to its surrounding public, it resists identifying with any single group by avoiding discussions of particular heritages.

David Favaloro, Director of Curatorial Affairs, also commented on how the diverse demography of the museum's immediate neighborhood intersects with its mission. The Lower East Side is characterized by "many competing voices that are trying to claim some space in that conversation about what we call heritage," said Favaloro. He continued:

Ruth Abram's genius was that this was going to be a place where Americans of a variety of different backgrounds, particularly European immigrant backgrounds, could come and find the common ground that they share and not just think of themselves as Jewish Americans or Italian Americans; that this would be a way to foster dialogue about the role of immigration in American identity.

At the museum, therefore, the staff uses the language of class more than of heritage to avoid representing individuals only in terms of their ethnic identity, a concept that Favaloro acknowledged does not necessarily conform to lived experience, but that furthers the museum's greater mission.

Annie Polland, Senior Vice President for Programs and Education at the Tenement Museum, expanded both Steinberg and Favaloro's ideas by describing the kind of identity that the Museum is attempting to address, a concept more nuanced than heritage in this context:

We don't use [the term heritage] a lot. If we were to use it, it would be our "American heritage." At the same time we don't disrespect the fact that visitors might be coming in search of their own specific family heritage, their own specific ethnic or immigrant group, but the idea of the museum is to see as much of the specificities of a particular 
family as needed to make them come alive, but on the other hand, to be telling the story in such a way that you're going to connect because it's a human story, a story of the working class, a story of a woman or of a man regardless of where they're from... In 97 Orchard, because we stop interpretation at 1935, we're not telling the stories of more recent immigrants, so if we rely on heritage, that would actually be counter to the community engagement of people in this neighborhood today... I think it's bigger than heritage. Maybe it's New York identity or New York American identity.

By transcending discrete heritages, the Tenement Museum preserves the past as a lived experience with which visitors can identify and empathize, and re-create, in the present.

\section{Conclusion}

In 2016, the Preservation Action Committee concluded its service to the Tenement Museum. For the three grant-funded years of its tenure, from 2012 to 2015, members oversaw new strategies of condition monitoring and implemented experimental conservation treatments. The written product of the collaboration is a 1,009 page Preservation Action Plan (PAP) that reports the assessment findings and recommends interventions in five year increments to allow for staff to "identify and address immediate concerns and hopefully allow for minimal loss of historic fabric."

With respect to the museum's Preservation Philosophy, a final line in the introduction states that "it is important to understand that all work conducted for the sake of preservation of 97 Orchard Street is undertaken as a way to not only proactively manage change but also to provide continued exemplary visitor experiences" (PAP, 5). Vigorous dialogue in the committee's final sessions addressed whether to edit the words "preservation," "conservation," and "restoration" in the statement of the museum's current Preservation Philosophy on the grounds that they may not fully reflect the ongoing work of the museum staff and consultants. Discussing this dilemma, a committee member read aloud the American Institute for Conservation definitions of terminology and the Secretary of Interior standards, all of which had informed the language of the museum's Preservation Philosophy. Architectural historian and Preservation Action Committee member Andrew Dolkart commented that the preservation process carried out in the Tenement Museum "does not conform to a parochial definition;" it is not "saving every nut and bolt." The group as a whole concurred that interpretation of the building, to the degree undertaken by the Tenement Museum, is not sufficiently accounted for in current official notions of the aim of preservation. "If this were totally about preservation and conservation," Judith Saltzman said, "we wouldn't be having this conversation. The Museum would not have the educational impact that it has. That was the first lesson that I learned on this project. It's the engagement of the visitor."

To convey the inextricable relationship between tangible and intangible heritage, folklorist Barbara Kirshenblatt-Gimblett refers to philosopher Stanley Eveling's concept of "a thing as a slow event" (Kirshenblatt-Gimblett 2017, 181). Both tangible and intangible forms of heritages, she comments, are modes of cultural production, metacultural performances in which people self-consciously curate culture (Kirshenblatt-Gimblett 2017, 178). They are inevitably 
interconnected and reliant upon individual agency and performance as the source of their meaning.

When people engage with material things and physical landscapes around them, such as 97 Orchard Street, they perform and re-perform their histories, values, and circumstances. The tangible and intangible are bridged as individuals activate the material world through unique perceptions of their connections to it. The Tenement Museum exemplifies this bridging of the tangible and the intangible, and the power of such a metacultural process. Walking through the hallways and apartment spaces of 97 Orchard Street, visitors apprehend and empathize with the material conditions and social experiences of the building's former residents, recreating the histories and meanings imbued in the building's physical reality.

\section{Notes}

Editor's Note: The preceding essay was presented by its author during the Fifth Forum on ChinaUS Folklore and Intangible Cultural Heritage: Bridging Tangible and Intangible Cultural Heritage in Ethnographic Museums and Heritage Sites, which was held at the Museum of International Folk Art in Santa Fe, New Mexico, in the United States on November 10-11, 2014. The conference was organized by the American Folklore Society and the China Folklore Society, with sponsorship from The Henry Luce Foundation. The conference was a part of the China-US Folklore and Intangible Cultural Heritage Project, specifically the sub-project on Intangible Cultural Heritage and Ethnographic Museum Practice. The Mathers Museum of World Cultures is an institutional participant in this project.

Author's Note: Special thanks to David Favaloro, Director of Curatorial Affairs at the Lower East Side Tenement Museum, for his archival research assistance.

1. Lower East Side Tenement Museum Conservation Management Plan, prepared by the Li/Saltzman Architects PC, Jablonski Berkowitz Conservation Inc., and Island Housewrights Corporation for the Lower East Side Tenement Museum, March 2006.

2. The United Nations Educational, Scientific, and Cultural Organization defines tangible and intangible heritage as follows: "tangible heritage includes buildings and historic places, monuments, artifacts, etc., which are considered worthy of preservation for the future. These include objects significant to the archaeology, architecture, science or technology of a specific culture... Intangible cultural heritage, also known as 'living heritage', refers to the practices, representations, expressions, knowledge and skills transmitted by communities from generation to generation." For more, visit: http://en.unesco.org/themes/intangible-culturalheritage\#sthash.el34dts4.dpuf (accessed February 5, 2015). In the case of the Tenement Museum, the staff is charged with both preserving the physical building as an historic landmark (tangible), and the social and cultural histories of its tenants (intangible) as reconstructed through oral history, archaeological, and archival research.

3. As stated on the Tenement Museum's website, accessed October 15, 2016, http://tenement.org/about.html. 


\section{References Cited}

Dolkart, Andrew. 2006. Biography of a Tenement House in New York City: An Architectural History of 97 Orchard Street. Charlottesville: University of Virginia Press.

Kirshenblatt-Gimblett, Barbara, 2017. "From Ethnology to Heritage: The Role of the Museum." In Folklife and Museums: Twenty-First-Century Perspectives, edited by C. Kurt Dewhurst, Patricia Hall, and Charlie Seemann, 177-92. Lanham, MD: Rowman and Littlefield.

Lower East Side Tenement Museum Archives. Accessed November 2013. http://tenement.org/encyclopedia/lower_landscape.htm.

Sciorra, Joseph. 1993. "Multivocality and Vernacular Architecture: The Our Lady of Mount Carmel Grotto in Rosebank, Staten Island.” In Studies in Italian American Folklore, edited by Luisa Del Giudice, 203-243. Logan: Utah State University Press.

Williams, Michael Ann, and M. Jane Young. 1991. "Grammar, Codes, and Performance: Linguistic and Sociolinguistic Models in the Study of Vernacular Architecture." Paper presented at the Vernacular Architecture Forum, Santa Fe, May 15-18.

Gabrielle A. Berlinger is an Assistant Professor of American Studies and Folklore at the University of North Carolina at Chapel Hill, where she is also the Babette S. and Bernard J. Tanenbaum Fellow in Jewish History and Culture. She is the author of Framing Sukkot: Tradition and Transformation in Jewish Vernacular Architecture (Bloomington: Indiana University Press, 2017) and a recent contributor to Buildings and Landscapes: The Journal of the Vernacular Architecture Forum.

https://doi.org/10.14434/mar.v12i1.13502 